\title{
Evaluation of Adhesive Defects using an Ultrasonic Pulse-reflection Technique
}

\author{
Naho HAMANO, Koji HANAOKA ${ }^{1}$, Kei EBIHARA ${ }^{1}$, \\ Minoru TOYODA and Toshio TERANAKA ${ }^{1}$ \\ Department of Prosthetic Dentistry, \\ ${ }^{1}$ Department of Operative Dentistry and Endodontics, \\ Kanagawa Dental College \\ 82 Inaoka-cho, Yokosuka-shi, Kanagawa 238-8580, Japan
}

Received October 15, 2002/Accepted December 25, 2002

\begin{abstract}
The purpose of this study was to examine the application of an ultrasonic pulse-reflection technique for the evaluation of adhesive defects. First, the sonic velocities in the enamel and dentin of human molars and bovine incisors were measured with a pulsar receiver attached to an ultrasonic transducer. The identification of the dentino-enamel junction and pulp-dentin interface using the ultrasonic method based on intrinsic sonic velocities showed good agreement with the actual measured thicknesses. Next, a cemented restoration with artificial faults was prepared. Half of the Au-Ag-Pd alloy plate area was cemented to the dentin slab using luting resin cement. The adhesive interface was evaluated with a high-resolution ultrasonic imaging system. Clear internal faults were evident from the ultrasonic tomogram. The findings of this study suggest that the ultrasonic pulse-reflection technique may be useful for inspecting and imaging structural defects of adhesive interfaces.
\end{abstract}

Key words: Ultrasonic pulse-reflection technique, Sonic velocity, Adhesive defect

\section{INTRODUCTION}

The importance of adhesion is widely recognized in the field of dentistry. Most evaluations of adhesion are performed by procedures such as the measurement of bonding strength ${ }^{1)}$, microleakage testing ${ }^{2)}$ and the microstructual evaluation ${ }^{3)}$ of the adhesive interface. However, these in vitro methods require destructive alterations of the adhered surfaces and cannot be applied to in vivo evaluations. In clinical practice, the development of adequate diagnostic methods for predicting the longevity of adhesion is desired. Ultrasonic imaging might be one of the key technologies that will enable the realization of such diagnostic methods. This nondestructive testing method can detect invisible changes in the internal tooth structure. Ultrasonic waves have a short wavelength, and sharp and straight directivity, so they not only can be transmitted and received easily, but they also have excellent distance resolution. In addition, since they consist of a mechanical wave motion, they are harmless to the living body.

In the field of dentistry, the first application of ultrasonic wave technology was executed by Baum et al. ${ }^{4)}$ with an ultrasonic transducer that had been used in ophthalmology to diagnose dental hard tissue. After that, this method was applied to 


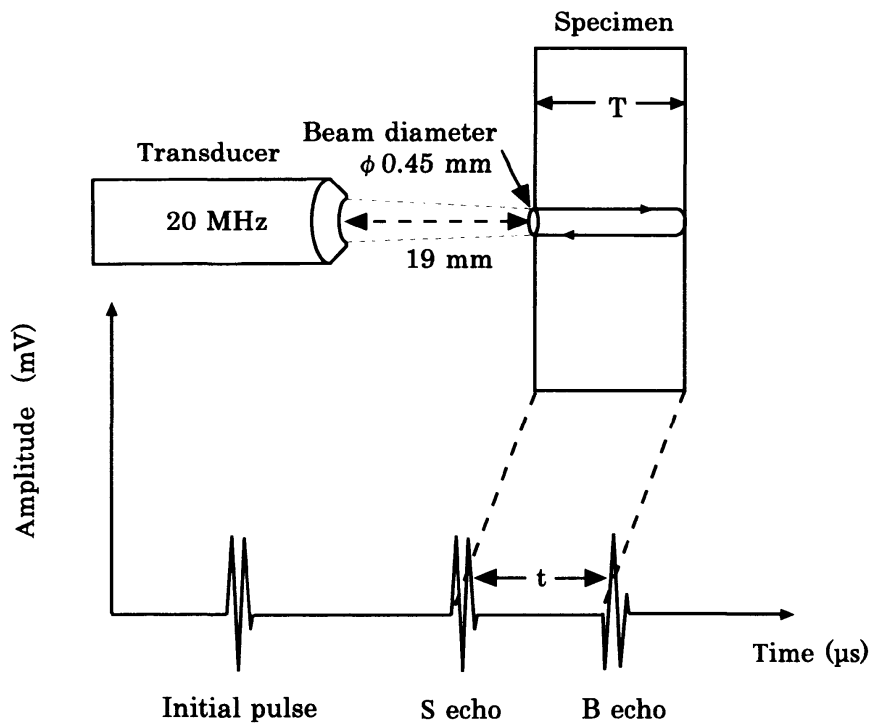

Fig. 1 Diagram representing measurement of sonic velocities.

$\mathrm{V}=2 \mathrm{~T} / \mathrm{t}$

$\mathrm{V}$ : Sonic velocity $(\mathrm{m} / \mathrm{sec})$

$\mathrm{T}$ : Thickness of specimen $(\mathrm{m})$

$\mathrm{t}$ : Time interval between pulse echoes $(\mathrm{sec})$

the diagnosis of periodontium ${ }^{5-8)}$, the measurement of the thickness of dental hard tissue $^{9-12)}$ and mucosa under the dental plate ${ }^{13-16)}$, and so forth. However, to date, the ultrasonic system has not been employed to evaluate the resin/dentin adhesion for diagnostic equipment.

The fundamental principle of the ultrasonic pulse-reflection technique is based on the following. When a pulsed longitudinal wave reaches an object consisting of two media, it will be partly transmitted and partly reflected at the surface of the first medium and at the boundary between the two media, due to the difference in their acoustic impedance. Structural information can be acquired from the echo wave that is reflected and returned. The signal amplitudes of the echo waves are displayed against the horizontal time axis as shown in Fig. 1. In addition, if there are any structural anomalies such as defects, voids or discontinuity in the object, the echo transit times and the echo amplitude of reflected echo waves will provide information about the location and depth of these structural differences ${ }^{17,18}$.

The purpose of this study was to examine the possible application of an ultrasonic pulse-reflection technique to image and diagnose adhesive defects. The two basic experiments conducted using this technique were: 1) the identification of the dentino-enamel junction (DEJ) and pulp-dentin interface (PDI); and 2) the detection of artificially induced internal faults in cemented cast restorations. 


\section{MATERIALS AND METHODS}

Fig. 2 shows the ultrasonic analyzing system used. It was composed of an ultrasonic pulsar receiver (Model 5900, Panametrics, Inc., Waltham, MA, USA), an ultrasonic focusing type transducer (M316, Panametrics, Inc., Waltham, MA, USA), and a digital oscilloscope (TDS3000, Tektronix, Inc., Wilsonville, OR, USA) to display amplitudes and transmit times of electrical echo signals. The transducer $(3.2 \mathrm{~mm}$ diameter element size; generating pulsed ultrasound waves of $20 \mathrm{MHz}$ ) was fixed perpendicular to the target. The following experiments were performed using a water immersion testing method. The experimental conditions for the pulsar receiver and characteristics of the focusing transducer are shown in Table 1 and Table 2, respectively.

1. Measurement of the sonic velocity and identification of DEJ and PDI

1) Measurement of sonic velocities in human and bovine dentin/enamel

Thirteen intact extracted human molars were randomly chosen, and a number of ap-
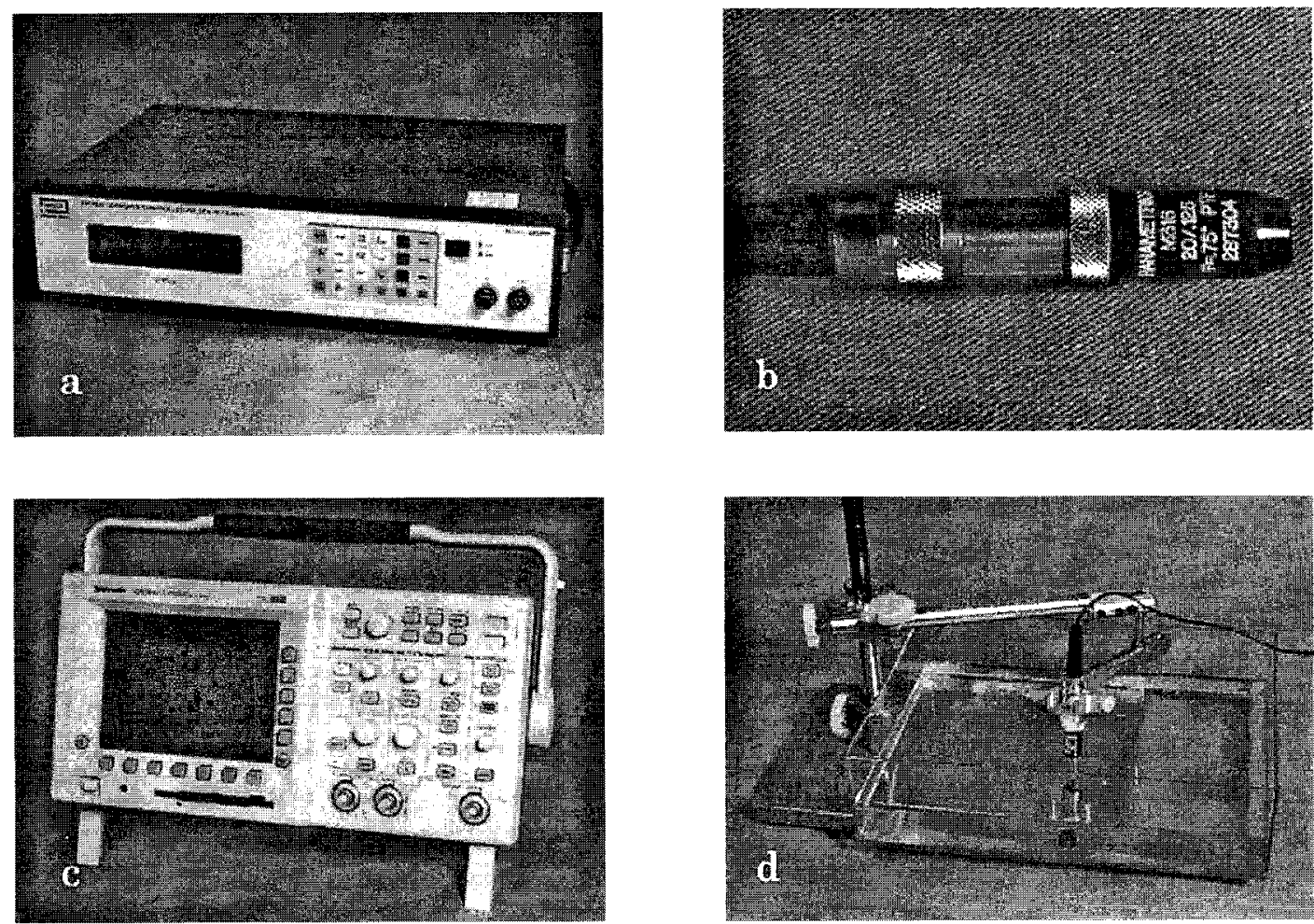

Fig. 2 Components of the ultrasonic system. a: Ultrasonic pulsar receiver (5900PR)

b: Ultrasonic transducer (M316)

c: Digital oscilloscope (TDS3000)

d: Measurement under water 


\begin{tabular}{cc} 
Table 1 Experimental conditions for the pulsar receiver \\
\hline Mode & Pulse/Echo \\
Pulse Repetition Frequency & $200 \mathrm{~Hz}$ \\
Energy & $32 \mu \mathrm{J}$ \\
Damping & $50 \Omega$ \\
High Pass Filter & $1 \mathrm{MHz}$ \\
Low Pass Filter & $200 \mathrm{MHz}$ \\
Attenuators & $18.0 \mathrm{~dB}$ \\
Gain & $40.0 \mathrm{~dB}$ \\
RF Output Phase & $180^{\circ}$
\end{tabular}

\begin{tabular}{cc} 
Table 2 Characteristics of & focusing transducer \\
\hline Frequency & $20 \mathrm{MHz}$ \\
Element size & $3.2 \mathrm{~mm} \phi$ \\
Focal distance & $19 \mathrm{~mm}$ \\
Beam diameter & $0.45 \mathrm{~mm} \phi$ \\
Pulse wide & $50 \mathrm{~ns}$ \\
\hline
\end{tabular}

proximately 1-mm-thick longitudinal sections were sliced mesiodistally using sectioning equipment (Isomet, Low Speed Saw, Buehler Ltd., Lake Bluff, IL, USA). The flat section at the functional cusp area where there was a large amount of enamel was selected for testing. In addition, rectangular samples (approximately $8 \times 5 \times 1 \mathrm{~mm}$ ) of dentin and enamel were prepared from the labial surfaces of bovine incisors. All specimens were polished with a lapping film $(75 \mu \mathrm{m}$ roughness) (Imperial, Lot CT47, Sumitomo 3M Ltd., Tokyo, Japan) under flowing water.

After the exact thickness of the flat samples $(\mathrm{T})$ was determined using digital calipers, the time intervals $(t)$ between the surface echo (S-echo) from the boundary between the water and the top surface of the specimen, and the bottom echo (Becho) from the boundary between the bottom surface of the specimen and the water were measured using the ultrasonic system (Fig. 1). The sonic velocities in dentin and enamel were calculated according to the following equation:

$$
\mathrm{V}=2 \mathrm{~T} / \mathrm{t}
$$

where $\mathrm{V}=$ Sonic velocity $(\mathrm{m} / \mathrm{sec})$,

$\mathrm{T}=$ Thickness of the specimen $(\mathrm{m})$,

$\mathrm{t}=$ Time interval between pulse echoes ( $\mathrm{sec}$ )

As the ultrasonic pulse wave reflected at the top and bottom surfaces of the specimen, the time intervals indicated the time needed for the ultrasonic wave to make a round trip within the specimen.

The sonic velocities of the groups were analyzed by one-way ANOVA at a significance level of $\mathrm{p}<0.05$. If significant differences were detected, further analysis was performed using Fisher PLSD. 


\section{2 ) Identification of DEJ and PDI}

Enamel/dentin blocks $(3 \times 5 \times 3 \mathrm{~mm})$ were prepared from the buccal crown surfaces of unpolished intact human molars. Rectangular enamel/dentin blocks $(5 \times 6 \times 3 \mathrm{~mm})$ were also cut from extracted bovine incisors. The upper and lower surfaces were polished according to the method previously mentioned.

Identification of the DEJ and PDI were performed with the ultrasonic pulsereflection technique using the measured sonic velocities. To measure the human teeth, several settings of the pulsar receiver were changed: the low pass filter was changed from $200 \mathrm{MHz}$ to $50 \mathrm{MHz}$, and the attenuators were lowered from $18 \mathrm{~dB}$ to $8 \mathrm{~dB}$ to obtain a clearer echo wave.

The locations of the DEJ and PDI in the human tooth specimens were estimated according to Equation (1) using the time intervals ( $t$ ) between each echo pulse on the echogram obtained and the measured sonic velocities $(\mathrm{V})$. Then, the specimens were sectioned at the location where the ultrasonic beam had penetrated in order to measure the true dimensions of each layer under the microscope with $0.01 \mathrm{~mm}$ as the minimum length of measurement.

2. Detection of internal faults in cemented cast restorations

Cemented cast restorations with artificial faults were prepared according to the following procedure. To make cast restorations, flat square plates $(10 \times 6 \times 1 \mathrm{~mm})$ of Au-Ag-Pd casting alloy (Castwell M.C. 12\% Gold, GC Co., Tokyo, Japan) were prepared. These surfaces were sandblasted with $70 \mu \mathrm{m}$ alumina and treated with Alloy Primer (Lot 00103A, Kuraray Co., Ltd., Osaka, Japan). Dentinal slabs $(12 \times 8 \times 1$ $\mathrm{mm}$ ) were obtained from extracted bovine incisors as adherents. Half of the dentinal slab was covered with a sheet of wax $(0.5 \mathrm{~mm}$ thick $)$. The other half was treated with ED primer (ED primer II Liquid A, Lot 00139A; Liquid B, Lot 00024A, Kuraray Co., Ltd., Osaka, Japan) for $60 \mathrm{sec}$ and dried with gentle air. Then, the Au-Ag-Pd alloy plates were cemented on the dentin slabs using a luting adhesive resin cement (Panavia Fluoro Cement, Lot 011138; A Paste, Lot 00094A; B Paste, Lot 000054A, Kuraray Co., Ltd., Osaka, Japan) according to manufacturer's instructions. After the bonded specimens were stored in a humidor for 24 hours, the wax was removed using boiling water.

Artificial faults at the dentin/casting adhesive interface were evaluated using a High Resolution Ultrasonic Imaging System (Panametrics, Inc., Waltham, MA, USA). This computer-controlled high-resolution scanning system offers C-scan imaging that can capture an accurate ultrasonic image in a horizontal direction. The transducer was fixed on an X-Y scanning device that scans on $0.1-\mathrm{mm}$ pitch (scan speed: 15 $\mathrm{mm} / \mathrm{sec}$ ). The radiation of the incident ultrasonic wave and the detection of the reflected echo wave were performed from the casting side of the specimen through this transducer. Output signals from the transducer were transferred to the memory board of the computer and were displayed as color-mapping images, depending on the amplitudes of the echo waves. Detection of internal faults in the cemented cast restorations was performed under two conditions, with and without marginal sealing 
of the nonbonded area using cyanoacrylate (Aronalpha, Konishi Co., Ltd., Osaka, Japan). An adequate amount of cyanoacrylate was applied carefully on the marginal free area of the dentin/casting specimen.

\section{RESULTS}

1. Measurement of the sonic velocity and identification of DEJ and PDI

Tables 3 and 4 show the mean sonic velocity and standard deviation in the enamel and dentin of human molars and bovine incisors. The sonic velocity in human enamel $(6,244 \mathrm{~m} / \mathrm{sec})$ was significantly higher than that in human dentin $(4,095 \mathrm{~m} /$ $\mathrm{sec})(\mathrm{p}<0.05)$. Sonic velocities in bovine enamel and dentin $(5,425 \mathrm{~m} / \mathrm{sec}$ and 3,663 $\mathrm{m} / \mathrm{sec}$, respectively) were significantly lower compared with those in human teeth $(\mathrm{p}<0.05)$.

Representative echograms of a human molar and bovine incisor are shown in Fig. 3. Both specimens demonstrated similar echo patterns that have three marked

Table 3 Sonic velocities in human enamel and dentin

\begin{tabular}{cccccc}
\hline Sample No. & Years & Gender & Type of tooth & Enamel $(\mathrm{m} / \mathrm{s})$ & Dentin $(\mathrm{m} / \mathrm{s})$ \\
\hline 1 & 53 & $\mathrm{~m}$ & 7 & $6,206.8$ & $4,000.0$ \\
2 & 20 & $\mathrm{~m}$ & 8 & $6,034.4$ & $4,166.6$ \\
3 & 55 & $\mathrm{~m}$ & 7 & $6,083.3$ & $4,244.1$ \\
4 & 28 & $\mathrm{f}$ & 8 & $6,250.0$ & $4,076.0$ \\
5 & 55 & $\mathrm{f}$ & 6 & $6,607.1$ & $4,111.1$ \\
6 & 22 & $\mathrm{~m}$ & 8 & $6,203.7$ & $4,187.5$ \\
7 & 57 & $\mathrm{~m}$ & 7 & $6,621.6$ & $4,083.3$ \\
8 & 23 & $\mathrm{f}$ & 8 & $6,093.7$ & $4,062.5$ \\
9 & 24 & $\mathrm{f}$ & 8 & $6,370.9$ & $4,114.5$ \\
10 & 24 & $\mathrm{f}$ & 8 & $6,136.3$ & $4,029.8$ \\
11 & 24 & $\mathrm{f}$ & 8 & $6,060.6$ & $4,166.6$ \\
12 & 35 & $\mathrm{~m}$ & 8 & $6,209.6$ & $4,010.4$ \\
13 & 22 & $\mathrm{f}$ & 8 & $6,290.3$ & $3,979.5$ \\
\hline & & & AVG & 6,244 & 4,095 \\
\end{tabular}

Table 4 Sonic velocities in bovine enamel and dentin

\begin{tabular}{ccc}
\hline Sample No. & Enamel $(\mathrm{m} / \mathrm{s})$ & Dentin $(\mathrm{m} / \mathrm{s})$ \\
\hline 1 & $5,267.8$ & $3,618.4$ \\
2 & $5,571.4$ & $3,666.6$ \\
3 & $5,514.7$ & $3,605.7$ \\
4 & $5,367.6$ & $3,650.0$ \\
5 & $5,530.3$ & $3,650.0$ \\
6 & $5,330.8$ & $3,698.9$ \\
7 & $5,390.6$ & $3,750.0$ \\
\hline AVG & 5,425 & 3,663 \\
SD & 114 & 49 \\
\hline
\end{tabular}




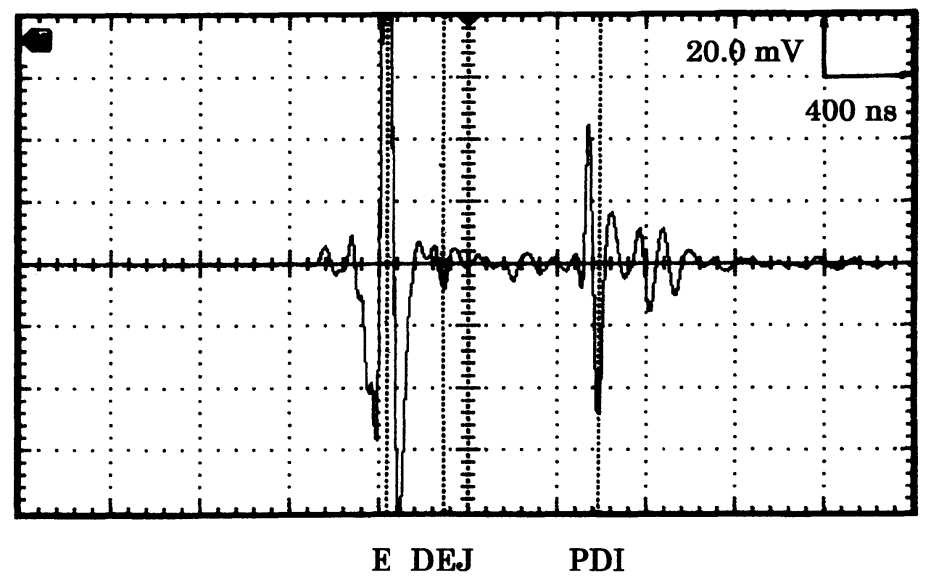

a

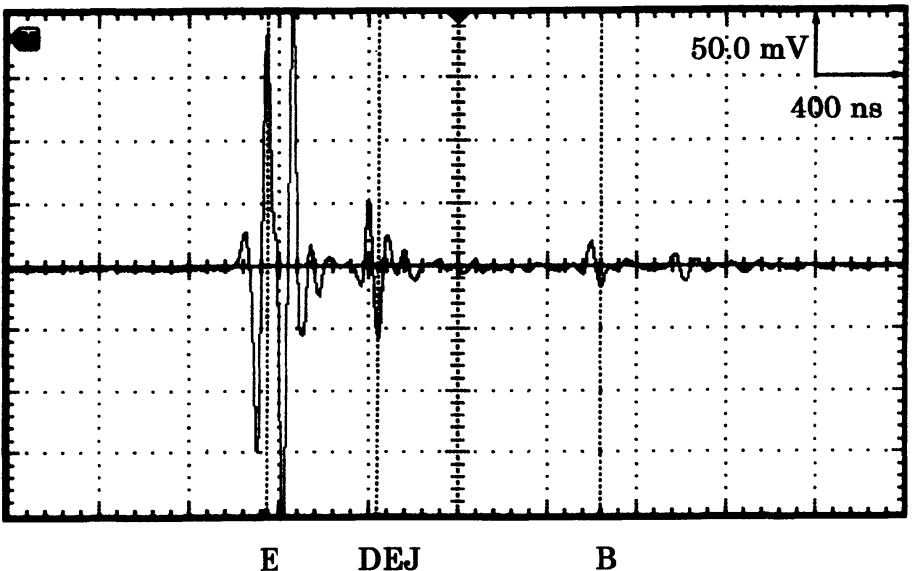

b

Fig. 3 Typical echo patterns of a human molar and a bovine incisor.

a: Pulse echoes from E, DEJ and PDI detected in a human molar. The estimated thicknesses of the enamel and dentin layers were $0.774 \mathrm{~mm}$ and $1.474 \mathrm{~mm}$, respectively.

b: Pulse echoes from E, DEJ and B detected in a bovine incisor. The estimated thicknesses of the enamel and dentin layers were $1.367 \mathrm{~mm}$ and $1.832 \mathrm{~mm}$, respectively.

echo pulses. These three echo pulses indicated the enamel surface (E), DEJ and PDI for the human teeth, and the bottom surface (B) for the bovine incisors. On the echogram of the human molar in Fig. 3a, the E-to-DEJ time interval was 248 nsec, and the DEJ-to-PDI time interval was $720 \mathrm{nsec}$. Using the measured sonic velocities, the enamel and dentin layers of this specimen were estimated to be $0.774 \mathrm{~mm}$ thick 
Table 5 Correlation coefficients of the estimated thickness and actual measured thicknesses

\begin{tabular}{cccc}
\hline Specimen & Estimated thickness & Actual measured thicknesses Correlation coefficient \\
\hline \multirow{3}{*}{ Human enamel } & 0.774 & 0.78 & \\
& 1.474 & 1.45 & 1 \\
& 0.999 & 1.01 & \\
& 0.799 & 0.81 & \\
Human dentin & 0.974 & 0.99 & 1 \\
& 1.474 & 1.48 & \\
& 0.868 & 0.88 & \\
Bovine enamel & 1.327 & 1.31 & \\
& 1.163 & 1.18 & \\
& 2.621 & 2.59 & \\
& 1.454 & 1.44 & \\
Bovine dentin & 1.345 & 1.35 & \\
& 0.868 & 0.88 & \\
& 0.738 & 0.75 & \\
& 1.367 & 1.37 & \\
& 1.868 & 1.88 & \\
& 1.832 & 1.81 & \\
\hline
\end{tabular}

and $1.474 \mathrm{~mm}$ thick, respectively. On the echogram of the bovine incisor in Fig. $3 \mathrm{~b}$, the E-to-DEJ time interval was $504 \mathrm{nsec}$, and the DEJ-to-B time interval was $1.00 \mu$ sec. Using sonic velocities, the estimated thickness of the enamel and dentin layers were indicated as $1.367 \mathrm{~mm}$ and $1.832 \mathrm{~mm}$, respectively.

From all data obtained, computed correlation coefficients of the estimated thickness and actual measured thicknesses of the specimens obtained from human and bovine dentin/enamel ranged from 0.975 to 1 , as shown in Table 5 .

2. Detection of internal faults in cemented cast restorations

Figs. $4 \mathrm{a}$ and $4 \mathrm{~b}$ represent the changes of repeated echo waves at the nonbonded and the bonded parts, respectively, of the cemented Au-Ag-Pd alloy plate/dentin slab, which sealed the margin of the nonbonded area using cyanoacrylate. In these reflected echo waves, one wave mass means one echo pattern that was formed by one wave's round trip.

A distinct difference was recognized between the echo patterns of these two areas. The amplitudes of the repeated echo waves (the echo amplitude) decreased gradually in the nonbonded area (Fig. 4a). On the other hand, a rapid decrease in the echo amplitude, which is a rapid attenuation of the echo wave, was observed in the bonded area (Fig. 4b).

C-scan images obtained from the relative intensity of amplitudes of the first and second echoes are shown in Fig. 5 (with marginal sealing) and Fig.6 (without marginal sealing). Internal faults were demonstrated clearly in a horizontal direction on 


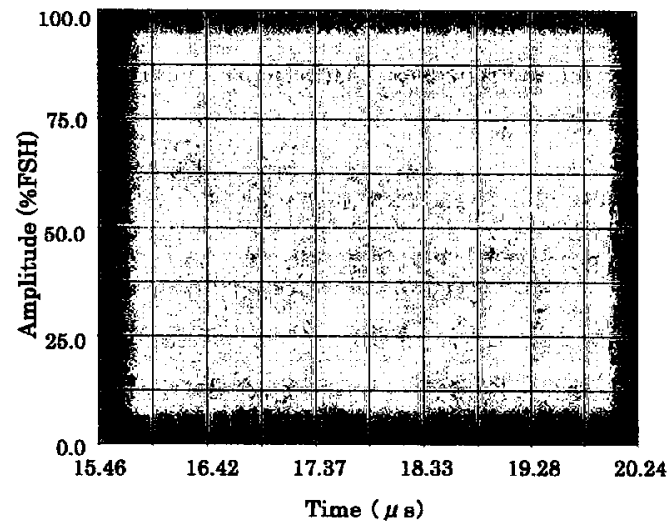

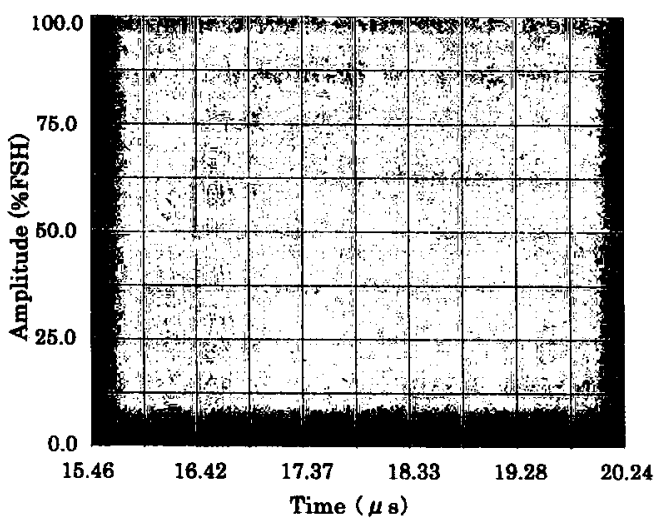

b

Fig. 4 Repeated echo waves of the cemented Au-Ag-Pd alloy plate/dentin slab at the bonded and the nonbonded parts filled with air.

a: Amplitudes of the repeated echo waves decreased gradually at the nonbonded part. b: The rapid decrease of echo amplitude, which is the attenuation of the echo wave, was recognized at the bonded part.

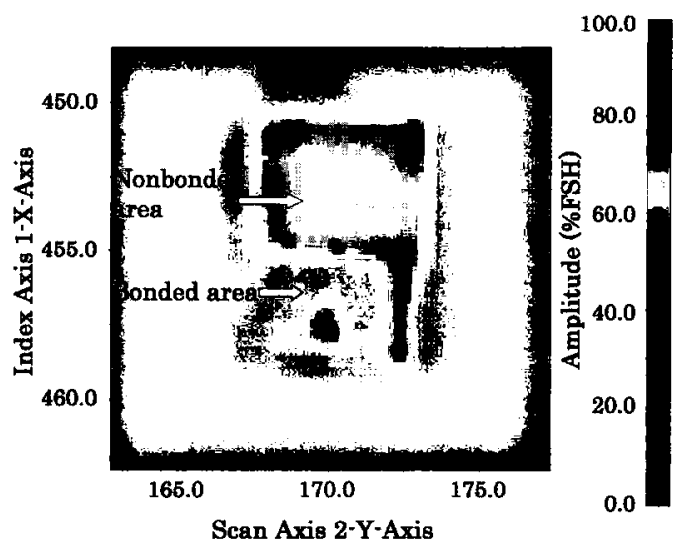

Fig. 5 C-scan imaging of the cemented $\mathrm{Au}$ Ag-Pd alloy plate/dentin slab with marginal sealing of the nonbonded area using cyanoacrylate.

Internal faults were demonstrated clearly on color mapping images of the ultrasonic tomograms using the relative intensity of amplitudes of the first and second echoes at all measuring points.
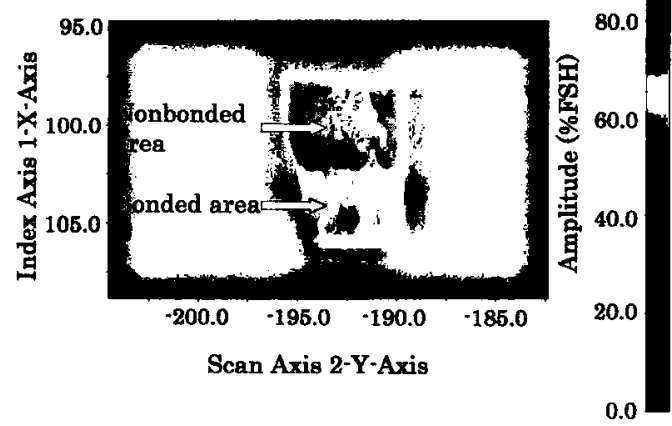

Fig. 6 C-scan imaging of the cemented AuAg-Pd alloy plate/dentin slab without marginal sealing of the nonbonded area with cyanoacrylate. 
the ultrasonic tomogram under both conditions. The upper bright-colored region indicates a nonbonded area. The lower dark-colored region indicates a bonded area. More detailed differences between the nonbonded area and the bonded area are shown clearly in the specimen with marginal sealing in Fig. 5.

\section{DISCUSSION}

In this study, we examined the adhesive defect by an ultrasonic pulse-reflection technique using an improved ultrasonic transducer and ultrasonic pulsar receiver with great accuracy. In fact, the pulsar receiver used for these measurements has excellent characteristics. Since the rising time of the sonic pulses is below $1 \mathrm{nsec}$, it can be adapted to the ultrasonic measurement using a high frequency (20 MHz), which allows precise measurement of thinner enamel and dentin. In addition, the ultrasonic transducer has high resolution and sensitivity in the high-frequency range. The ability to measure the thickness of a test sample depends on the limit of readability between the echo waves on the oscilloscope and the pulse persistence time. As the pulse width of the transducer used in this study is $50 \mathrm{nsec}$ (Table 2), it can measure samples to a minimum thickness of $0.1 \mathrm{~mm}$ when the acoustic velocity of the material (dentin) is $4,000 \mathrm{~m} / \mathrm{s}$. Furthermore, this focused transducer with a beam diameter (d) of $0.45 \mathrm{~mm}$ at the focal distance of $19 \mathrm{~mm}$ (which can minimize the measurement range as much as possible) was used to obtain a clear waveform.

\section{Measurement of the sonic velocity and identification of DEJ and PDI}

Various values have been reported previously ${ }^{17-23)}$ for the sonic velocity of human dental hard tissues. In particular, significant variations have been found as the sonic velocities in human enamel ${ }^{17-22)}$ (from $4,500 \mathrm{~m} / \mathrm{s}$ to $6,250 \mathrm{~m} / \mathrm{s}$ ). The measured sonic velocity in enamel in this study $(6,244 \mathrm{~m} / \mathrm{sec})$ was in close agreement with the findings Barber et al. reported $(6,250 \mathrm{~m} / \mathrm{sec})^{22)}$. For human dentin, sonic velocities ranging from $3,600 \mathrm{~m} / \mathrm{s}$ to $4,570 \mathrm{~m} / \mathrm{s}$ have been reported ${ }^{17-20,22,23)}$. Actually, the measured velocity in dentin $(4,095 \mathrm{~m} / \mathrm{sec})$ in the present experiment was within this range and was significantly lower than that in human enamel $(\mathrm{p}<0.05)$.

On the other hand, limited ranges of sonic velocities, which are significantly lower $(p<0.05)$ than those of human teeth, have been reported in the enamel and dentin of bovine incisors. Ranges from $5,400 \mathrm{~m} / \mathrm{s}$ to $6,030 \mathrm{~m} / \mathrm{s}$ for bovine enamel, and from $3,400 \mathrm{~m} / \mathrm{s}$ to $3,630 \mathrm{~m} / \mathrm{s}$ for bovine dentin have been reported ${ }^{21,22,24)}$. The sonic velocities obtained in the present study for bovine enamel and dentin $(5,425$ $\mathrm{m} / \mathrm{sec}$ and $3,663 \mathrm{~m} / \mathrm{sec}$, respectively) were similar to the results of previous studies.

Theoretically, sound velocity $(\mathrm{v})$ is defined by two mechanical properties of materials: elastic modulus $(\mathrm{E})$ and density $(\rho)$. Therefore, the above ranges of sonic velocity in human teeth may be explained by many factors such as the type of tooth, the location of the measurement, and the oral environment, in addition to technical factors such as different measurement systems and different techniques. Furthermore, it can be expected that pathological structural changes such as caries, sclerotic 
dentin, and the degree of calcification may contribute significantly to the sonic velocity $^{25-28)}$.

The clear detection of three echo pulses from E, DEJ and PDI for human teeth and B for bovine incisors in Fig. 3, and higher correlation coefficients of the estimated thickness and actual measured thicknesses of the enamel and dentin of the test specimens suggested that the identification of the DEJ and PDI (or B) by the ultrasonic pulse-reflection technique was very accurate and effective.

However, we had difficulty in placing the transducer during measurements of human teeth. Unless the ultrasonic transducer was applied vertically to all interfaces, including the surface, clear reflected waves were not obtained. The surface roughness of the specimen and the curvature of the reflecting surface, such as the pulp wall, were suggested to have a rather adverse effect on the detection of echo waves. In the clinical use of the ultrasonic pulse reflection technique, further improvement, such as development of a solid fixture for the transducer, is required.

\section{Detection of internal faults in cemented cast restorations}

The dislodgment of a cemented cast restoration generally is caused by the development of secondary caries at the margin and/or the failure or dissolution of the luting cement at the cement/casting interface under excessive occlusal loading. Reliable methods to predict the adhesive failure are desirable to detect secondary caries detected at an early stage and prevent its progression. In this study, ultrasonic examination of internal faults in cemented $\mathrm{Au}-\mathrm{Ag}-\mathrm{Pd}$ alloy plate/dentin slabs was conducted to evaluate it as a possible diagnostic tool for oral examinations.

As shown in Figs. $4 \mathrm{a}$ and $4 \mathrm{~b}$, the marked differences in repeated echo waves at bonded and nonbonded areas were attributed to the presence or absence of luting cement since all other variables were controlled. As the margin of the nonbonded area was sealed using cyanoacrylate, the space in the nonbonded area was filled with air. It was suggested that the presence of air completely intercepted the transmission of the pulse wave to bovine dentin, and only repeated echo waves from the surface and bottom of the Au-Ag-Pd alloy plate were detected with no other losses. As a consequence, the gradual decrease of echo amplitude was recognized, as shown in Fig. 4a.

On the other hand, the rapid decrease of the repeated echo amplitude, which is an attenuation of the echo wave, was evident at the bonded area (Fig. 4b). This attenuation may be explained by the superior ultrasonic transmission of the resin cement. Since pulse waves pass through the resin cement into dentin, a rapid decrease in the echo intensity might be caused by direct absorption, scattering and dispersion by the specimen itself and all the boundaries in the specimen consisting of metal, cement and dentin.

Furthermore, internal faults were clearly demonstrated on the ultrasonic tomograms during C-scan imaging (Fig.5). For practical clinical application, visualization of internal faults by color mapping on an ultrasonic tomogram is more effective than by differences in waveforms. More detailed horizontal scanning may enable the quantitative evaluation of the vertical dimensions of internal faults. 
In the actual oral environment, the spaces within the faults in cemented restorations will be occupied by liquid such as saliva and oral fluids, as is the case when nonbonded areas are not sealed. In general, the transmission and reflection of ultrasonic waves can be explained by the difference of acoustic impedance, which is dependent on a product of its density $(\rho)$ and sonic velocity (v). As the acoustic impedance of liquid is closer to that of luting cement compared with that of air, it will probably be difficult to detect faults in specimens with no marginal sealing. However, clear visualization by color mapping was demonstrated on the C-scan imaging (Fig.6). This result suggested that the high resolution ultrasonic imaging system used in this study has a superior ability to easily distinguish differences in the acoustic impedance of liquid and luting cement.

For actual clinical applications, further miniaturization of the ultrasonic transducer and redesigning it into a contra angle will be taken into consideration since the ultrasonic transducer used in this study was straight and relatively long. Moreover, the difference between the acoustic impedance of a vital tooth and an extracted tooth should also be considered.

\section{CONCLUSIONS}

1. The sonic velocity in human enamel $(6,244 \mathrm{~m} / \mathrm{sec})$ was significantly higher than that in human dentin $(4,095 \mathrm{~m} / \mathrm{sec})(\mathrm{p}<0.05)$. The sonic velocities in bovine enamel and dentin showed significantly lower values $(5,425 \mathrm{~m} / \mathrm{sec}$ and $3,663 \mathrm{~m} / \mathrm{sec}$, respectively) in comparison with those in human teeth $(\mathrm{p}<0.05)$.

2. The identification of the DEJ and PDI (or B for bovine incisors) in human molars by an ultrasonic pulse-reflection technique was very accurate and showed good agreement with the actual measured thickness.

3. A distinct difference was recognized between the echo patterns at the bonded and the nonbonded parts of a cemented $\mathrm{Au}-\mathrm{Ag}-\mathrm{Pd}$ alloy plate/dentin slab. Internal faults were demonstrated clearly on color mapping images of the ultrasonic tomogram.

4. The above results suggested that the ultrasonic pulse-reflection technique has the potential to be an accurate diagnostic tool for evaluating adhesive defects.

\section{ACKNOWLEDGEMENTS}

This work was performed at Kanagawa Dental College, Research Center of Advanced Technology for Craniomandibular Function and supported in part by grants-in-aid for Bioventure Research and Scientific Research (A) (No.12307045), from the Japanese Ministry of Education, Science, and Culture.

\section{REFERENCES}

1) Tao, L. and Pashley, D. H.: Dentin perfusion effects on shear bond strengths of bonding agents to dentin, Dent Mater $5: 181-184,1989$.

2) Sano, H., Takatsu, T., Ciucchi, B., Horner, J. A., Matthews, W. G. and Pashley, D. H.: 
Nanoleakage: leakage within the hybrid layer, Oper Dent $20: 18-25,1995$.

3) Harnirattisai, C., Inokoshi, S., Shimada, Y. and Hosoda, H.: Interfacial morphology of an adhesive composite resin and etched caries-affected dentin, Oper Dent $17: 222-228,1992$.

4) Baum, G., Greenwood, I., Slawski, S. and Smirnow, R.: Observation of internal structures of teeth by ultrasonography, Science $139: 495-496,1963$.

5) Sawada, K., Fujimasa, T. and Sunada, I.: Ultrasonography of the periodontal tissue, $J$ Jpn Soc Periodontol 26(1): 88-93, 1984. (in Japanese)

6) Muraoka, Y.: Examination of periodontal tissue with the ultrasonic apparatus - Survey of the marginal form of alveolar bone-, $J J p n$ Soc Periodontol 24(1):40-53, 1982. (in Japanese)

7) Muraoka, Y., Sueda, T. and Kinoshita, S.: Examination of periodontal tissue with the ultrasonic apparatus - Measurements of the thickness of gingiva, alveolar mucosa and alveolar bone-, $J$ Jpn Soc Periodontol 24(4):601-606, 1982. (in Japanese)

8) Ohshima, K.: Application of ultrasonography to periodontal diagnosis 1. Standardization of examination, J Jpn Soc Periodontol 31(1) : 235-240, 1989. (in Japanese)

9) Morozumi, M.: Measurement of the dentin thickness with an ultrasonic pulse-echo technique - The longitudinal sonic velocity in human dentin-, $J$ Jpn Prosthodont Soc 29(1): 15-29, 1985. (in Japanese)

10) Morozumi, M., Shiozawa, I. and Tabata, T.: The development of ultrasonic diagnostic equipment for dental use, J Jpn Prosthodont Soc 31(2):381-388, 1987. (in Japanese)

11) Komatsu, M. and Okuda, R.: Measurement of the non-instrumented remaining dentin thickness by an ultrasonic pulse-reflection technique, Jpn $J$ Conserv Dent 24(2) : 225-233, 1981. (in Japanese)

12) Komatsu, M. and Okuda, R.: Determination of the residual dentin thickness by an ultrasonic pulse reflection technique Part2. Measurement of molar dentin, Jpn J Conserv Dent 37(5) : 1463-1469, 1994. (in Japanese)

13) Kobayashi, K., Suzuki, T., Kimura, M., Tanaka, S., Uchida, H. and Nagao, M.: Application of ultrasonic pulse-echo method in the region of prosthodontics -Equipment and ultrasonagraph-, $J$ Jpn Prosthodont Soc 30(3):684-690, 1986. (in Japanese)

14) Uchida, H., Kobayashi, K. and Nagao, M.: Measurement in vivo of masticatory mucosal thickness with $20 \mathrm{MHz}$ B-mode ultrasonic diagnostic equipment, $J$ Dent Res 68:95-100, 1989.

15) Terakura, T.: Non-invasive thickness measurement of the oral soft tissue, $J J p n$ Prosthodont Soc 30(6) : 1402-1411, 1986. (in Japanese)

16) Terakura, T.: A study on thickness of the oral soft tissue - Usefulness in diagnosis for complete dentures-, J Jpn Prosthodont Soc 32(3):546-560, 1988. (in Japanese)

17) Lees, S. and Barber, F. E.: Looking into teeth with ultrasound, Science $161: 477-478,1968$.

18) Kossoff, G. and Sharpe, C. J.: Examination of the contents of the pulp cavity in teeth, Ultrasonics $4: 77-83,1966$.

19) Lees, S. and Barber, F. E.: Looking into the tooth and its surfaces with ultrasonics, Ultrasonics 9 : 95-100, 1971.

20) Reich, F. R., Brenden, B. B. and Porter, N. S.: Ultrasonic imaging of teeth, (Privately Issued); Report of Battelle Memorial Institute, Pacific Northwest Laboratory, Richland, Washington, 1967.

21) Lees, S.: Specific acoustic impedance of enamel and dentin, Archs Oral Biol 13 : 1491-1500, 1968.

22) Barber, F.E., Lees, S., Lobene, R. R.: Ultrasonic pulse-echo measurements in teeth, Archs Oral Biol 14 : 745-760, 1969.

23) Ng, S. Y., Payne, P. A., Cartledge, N. A. and Ferguson, M. W. J.: Determination of ultrasonic velocity in human enamel and dentine, Archs Oral Biol 34:341-345, 1989.

24) Gilmore, R. S., Pollack, R. P. and Katz, J. L: Elastic properties of bovine dentin and enamel, Archs Oral Biol 15 : 787-796, 1969.

25) Peck, S. D., Rowe, J.M. and Briggs, G. A. D.: Studies on sound and carious enamel 
with the quantitative acoustic microscope, $J$ Dent Res $68: 107-112,1989$.

26) Peck, S. D. and Briggs, G. A. D.: A scanning acoustic microscope study of the small caries lesion in human enamel, Caries Res $20: 356-360,1986$.

27) Peck, S. D. and Briggs, G. A. D.: The caries lesion under the scanning acoustic microscope, Adv Dent Res 1(1) : 50-63, 1987.

28) Lees, S., Gerhard Jr, F. B. and Oppenheim, F. G.: Ultrasonic measurement of dental enamel demineralization, Ultrasonics $11: 269-273,1973$. 